\title{
Code Red will become Code Blue for humanity: an urgent call for action in the anesthesia community
}

\author{
Vivian H. Y. Ip, MBChB, FRCA (1) Rakesh V. Sondekoppam, MBBS, MD • \\ Timur J. P. Özelsel, MD, DESA
}

Received: 21 August 2021/Revised: 5 September 2021/Accepted: 8 September 2021

(C) Canadian Anesthesiologists' Society 2021

Keywords Code red for humanity .

sustainable healthcare .

environmentally-sustainable anesthesia .

healthcare education

To the Editor,

Climate change has become an urgent matter as the headlines across the globe focus on "Code Red for humanity" in the wake of the release of the first part of the Sixth Assessment Report of the Intergovernmental Panel on Climate Change (IPCC) on 9 August 2021. ${ }^{1}$ Healthcare professionals are in a dilemma given that climate change is detrimental to human health, but at the same time, healthcare is a major contributor to carbon emission. $^{2}$ Given the ensuing situation, healthcare providers have the moral obligation to implement environmentally sustainable initiatives to mitigate our environmental burden.

The sterile operating room (OR) environment and the requirements of anesthetics create a huge environmental burden through the use of disposable items, plastic packaging, volatile agents, and pharmaceutical products, to name just a few.

For anesthesia alone, there are strategies to reduce carbon dioxide emission as previously outlined in our

V. H. Y. Ip, MBChB, FRCA ( $₫)$ · T. J. P. Özelsel, MD, DESA

Department of Anesthesia and Pain Medicine, University of

Alberta Hospital, Edmonton, AB, Canada

e-mail: hip@ualberta.ca

R. V. Sondekoppam, MBBS, MD

Department of Anesthesia, University of Iowa Hospitals and

Clinics, Iowa City, IA, USA article with the 3R's (reduce, refine, and replace) approach. ${ }^{3}$ These strategies require a mindset for practice change, such as using sevoflurane with minimal fresh gas flow. A recent systematic review has challenged the longheld myth that minmal-flow sevoflurane anesthesia cannot be safely used because of renal impairment. ${ }^{4}$ Furthermore, newer, advanced anesthetic machines with closed breathing circuits enabling automatic metabolic-flow which outperform manual adjustment of anesthetics in cost and environmental standpoint should be approved and available worldwide. With the need to improve OR efficiency, especially in the SARS-CoV-2 era, many use desflurane with the misconception that it speeds emergence while discounting its heavy environmental burden. Despite the quick offset of desflurane compared with sevoflurane, a randomized controlled trial showed that even in morbidly obese patients, desflurane did not produce any difference in extubation times with a carefully titrated anesthetic concentration. ${ }^{5}$ Generally, a greater emphasis should be placed on the use of regional anesthesia (RA) as it presumably reduces emissions and resource use compared with general anesthesia, although more robust research is required to quantify the true environmental impact of RA. ${ }^{2}$ Since the COVID-19 pandemic, many institutions have already employed sole RA for superficial and extremity surgeries to avoid aerosol generation. While this requires surgical team cooperation and expertise in RA, it is achievable. It also improves postoperative analgesia and increases OR efficiency by reducing induction and emergence times, as well as increasing postanesthesia care unit throughput. The culture of heavy reliance on single-use devices also needs to be addressed urgently by placing sustainable alternatives at the forefront since the finite resources on this planet do not support the "one and 
done" mentality. Furthermore, education on the environmental impact and sustainability measures in medicine and anesthesia should be provided through mandatory continuous professional development and an integrated curriculum, not only for anesthesiologists and medical students but also for hospital management and patients. This will increase awareness and accountability across healthcare organizations, which will lead to policy changes and foster responsible stewardship of our environment both within medical institutions and our daily lives.

The IPCC report has raised the alarm about the impending code red for humanity, and now the medical fraternity needs to get together and find solutions for a sustainable future in which humanity can thrive once more. Suggestions like the ones above are the low-hanging fruit-solutions that can be implemented today to reduce the impact we have in our daily practice. Akin to the building industry having to replace toxic asbestos, healthcare in general and anesthesia in particular will need to reinvent itself and find a way to replace the toxic practice we have today before the need to call code blue for humanity.

Disclosures None.

Funding statement None.
Editorial responsibility This submission was handled by Dr. Philip M. Jones, Deputy Editor-in-Chief, Canadian Journal of Anesthesial Journal canadien d'anesthésie.

\section{References}

1. Intergovernmental panel on climate change (IPCC). Climate change 2021: the physical science basis. Sixth Assessment report. Available from URL: IPCC_AR6_WGI_Full_Report.pdf (accessed September 2021).

2. Petre MA, Malherbe $S$. Environmentally sustainable perioperative medicine: simple strategies for anesthetic practice. Can J Anesth 2020; 67: 1044-63

3. Ozelsel TJ, Sondekoppam RV, Ip VH, Tsui BC. Re-defining the 3R's (reduce, refine, and replace) of sustainability to minimized the environmental impact of inhalational anesthetic agents. Can J Anesth 2019; 66: 249-54.

4. Sondekoppam RV, Narsingani KH, Schimmel TA, McConnell BM, Buro K, Ozelsel TJ. The impact of sevoflurane anesthesia on postoperative renal function: a systematic review and metaanalysis of randomized-controlled trials. Can J Anesth 2020; 67: 1595-623.

5. Arain SR, Barth CD, Shankar H, Ebert TJ. Choice of volatile anesthetic for the morbidly obese patient: sevoflurane or desflurane. J Clin Anesth 2005; 17: 413-9.

Publisher's Note Springer Nature remains neutral with regard to jurisdictional claims in published maps and institutional affiliations. 